Research Paper

\title{
Inhibition of Lipopolysaccharide-Induced Inflammatory and Oxidative Responses by Trans-cinnamaldehyde in C2C12 Myoblasts
}

Cheol Park ${ }^{1}$, Hyesook Lee, ${ }^{2,3}$, Suhyun Hong2,3, Ilandarage Menu Neelaka Molagoda ${ }^{4}$, Jin-Woo Jeong 5 ,

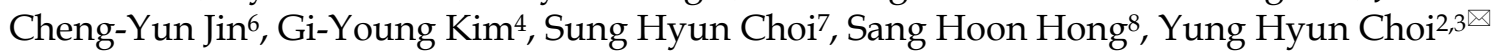

1. Division of Basic Sciences, College of Liberal Studies, Dong-Eui University, Busan 47340, Republic of Korea.

2. Anti-Aging Research Center, Dong-eui University, Busan 47340, Republic of Korea.

3. Department of Biochemistry, Dong-eui University College of Korean Medicine, Busan 47227, Republic of Korea.

4. Department of Marine Life Sciences, School of Marine Biomedical Sciences, Jeju National University, Jeju 63243, Republic of Korea.

5. Nakdonggang National Institute of Biological Resources, Sangju 37242, Republic of Korea.

6. School of Pharmaceutical Sciences, Zhengzhou University, Henan 450001, China.

7. Department of System Management, Korea Lift College, Geochang 50141, Republic of Korea.

8. Department of Internal Medicine, Dong-eui University College of Korean Medicine, Busan 47227, Republic of Korea.

$\square$ Corresponding author: Yung Hyun Choi, Department of Biochemistry, Dongeui University College of Korean Medicine, 52-57, Yangjeong-ro, Busanjin-gu, Busan 47227, Republic of Korea, E-mail: choiyh@deu.ac.kr

(C) The author(s). This is an open access article distributed under the terms of the Creative Commons Attribution License (https://creativecommons.org/licenses/by/4.0/). See http://ivyspring.com/terms for full terms and conditions.

Received: 2021.02.07; Accepted: 2021.04.12; Published: 2021.04.23

\begin{abstract}
Background: Trans-cinnamaldehyde (tCA), a bioactive component found in Cinnamomum cassia, has been reported to exhibit anti-inflammatory and antioxidant effects, but its efficacy in muscle cells has yet to be found. In this study, we investigated the inhibitory effect of tCA on inflammatory and oxidative stress induced by lipopolysaccharide (LPS) in $\mathrm{C} 2 \mathrm{C} 12$ mouse skeletal myoblasts.

Methods: To investigate the anti-inflammatory and antioxidant effects of tCA in LPS-treated $\mathrm{C} 2 \mathrm{Cl} 2$ cells, we measured the levels of pro-inflammatory mediator, cytokines, and reactive oxygen species (ROS). To elucidate the mechanism underlying the effect of tCA, the expression of genes involved in the expression of inflammatory and oxidative regulators was also investigated. We further evaluated the anti-inflammatory and antioxidant efficacy of tCA against LPS in the zebrafish model.

Results: tCA significantly inhibited the LPS-induced release of pro-inflammatory mediators and cytokines, which was associated with decreased expression of their regulatory genes. tCA also suppressed the expression of Toll-like receptor 4 (TLR4) and myeloid differentiation factor, and attenuated the nuclear translocation of nuclear factor-kappa B (NF-KB) and the binding of LPS to TLR4 on the cell surface in LPS-treated $\mathrm{C} 2 \mathrm{Cl} 2$ cells. Furthermore, tCA abolished LPS-induced generation of ROS and expression levels of ROS producing enzymes, NADPH oxidase 1 (NOX1) and NOX2. However, tCA enhanced the activation of nuclear translocation of nuclear factor-E2-related factor 2 (Nrf2) and the expression of heme oxygenase-1 (HO-1) in LPS-stimulated $\mathrm{C} 2 \mathrm{Cl} 2$ myoblasts. In addition, tCA showed strong protective effects against NO and ROS production in LPS-injected zebrafish larvae.

Conclusions: Our findings suggest that tCA exerts its inhibitory ability against LPS-induced inflammatory and antioxidant stress in $\mathrm{C} 2 \mathrm{Cl} 2$ myoblasts by targeting the TLR4/NF-KB, which might be mediated by the NOXs and Nrf2/HO-1 pathways.
\end{abstract}

Key words: Trans-cinnamaldehyde, inflammation, oxidative stress, TLR4/NF-kB, Nrf2/HO-1.

\section{Introduction}

As the largest tissue and one of the most active metabolic organs in the body, skeletal muscles play a key role in supporting body structures, controlling movement and storing energy. Skeletal muscle has also been recognized as one of the endocrine organs that produce and release cytokines, metabolites, and 
hormones that are important for maintaining human homeostasis [1,2]. In addition, because skeletal muscle expresses abundant toll-like receptor (TLR) 4 , it is sensitive to circulating endotoxins such as lipopolysaccharide (LPS), a component of the extracellular membrane of Gram-negative bacteria $[3,4]$. In muscle cells stimulated by circulating LPS, the expression of inflammatory cascade effector enzymes and cytokines is increased by activation of the TLR4-mediated intracellular signaling pathways, including nuclear factor-kappa B (NF-kB) $[4,5]$. Nitric oxide (NO) and prostaglandin $\mathrm{E}_{2} \quad\left(\mathrm{PGE}_{2}\right)$ are representative pro-inflammatory mediators, and pro-inflammatory cytokines such as tumor necrosis factor-alpha (TNF-a), interleukin (IL)-6, IL-1 $\beta$, and interferon- $\gamma$ facilitate inflammation [6,7]. Moreover, the expression of inducible NO synthase (iNOS) and cyclooxygenase-2 (COX-2), which are involved in the production of $\mathrm{NO}$ and $\mathrm{PGE}_{2}$, respectively, is positively correlated with the expression of pro-inflammatory cytokines $[8,9]$.

On the other hand, reactive oxygen species (ROS) and related species, which are required for proper physiological function under normal conditions, serve as important signaling molecules that are closely related to host defense responses. However, oxidative stress, characterized by the excessive production of ROS, contributes to the progression of the inflammatory response and multiple diseases [10,11]. LPS can induce and accelerate oxidative stress along with the inflammatory cascade. In this respect, accumulated evidences established that LPS-induced inflammation and oxidative stress is closely related to several pathological conditions including endometritis, periodontitis and mastitis [12-14]. Upon the LPS stimulation of muscle cells, the production of ROS is increased, contributing to the manifestation of inflammation, and overproduced inflammatory factors may promote excessive ROS production [4,15]. Currently, non-steroidal anti-inflammatory drugs are widely used to suppress inflammatory symptoms and relieve oxidative stress, but various side effects have been reported from long-term use $[16,17]$. Therefore, research on reliable and effective alternative agents for the prevention and treatment of various diseases is urgently required.

Trans-cinnamaldehyde ( $\mathrm{tCA}$ ) is one of the major phytochemical constituents isolated from the stem bark of Cinnamomum cassia (L.) J. Presl (Cinnamon), which is frequently used in traditional medicine for the prevention and treatment of various diseases such as ischemia, anxiety, arrhythmia, indigestion, diabetes, gastritis, blood circulation disorders, and so on [18-20]. A number of previous studies have shown that tCA has a variety of beneficial pharmacological effects, including anti-inflammatory, antioxidant, anti-diabetic, anti-obesity, neuroprotective, and anti-tumor effects in a number of in vitro and in vivo models [21-27]. As an example of the anti-inflammatory efficacy of tCA, Wang et al. [28] recently reported that this compound has a beneficial effect on inflammation-mediated depression, and possible mechanisms may include blocking the NF-kB pathway. Xia et al. [29] also suggested that the anti-inflammatory of tCA could be mediated by modulating the NF- $\mathrm{KB}$ signaling pathway in an osteoarthritis model. Additionally, tCA has been reported to inhibit the inflammatory response in LPS-stimulated monocytes and microglia by suppressing the activity of NF-kB [30,31]. These previous studies suggest that inhibition of the NF-kB signaling pathway plays a central role in the anti-inflammatory efficacy of tCA. Moreover, the exogenous addition of tCA has been shown to induce the expression of nuclear factor-E2-related factor 2 (Nrf2) and heme oxygenase-1 (HO-1), thereby increasing the effect of treadmill exercise on learning and memory in cognitive impaired mice [32]. These results well support the previous studies that Nrf2 plays a key role in the protective effect of tCA against oxidative stress-induced lung fibroblast and hippocampus injury [33,34] suggesting that tCA may have strong potential in the prevention or treatment of diseases associated with inflammatory and oxidative stress. However, the correlation between the anti-inflammatory and antioxidant effects of tCA in muscle cells has not been investigated yet. Therefore, in this study, we investigated the inhibitory effect of tCA on the inflammatory and oxidative reactions induced by LPS using C2C12 mouse skeletal muscle cells. We also demonstrated the anti-inflammatory and antioxidant potential of tCA in the zebrafish larvae model.

\section{Materials and Methods}

\section{Cell culture}

The $\mathrm{C} 2 \mathrm{C} 12$ cell line, an immortalized mouse myoblast cell line, was purchased from the American Type Culture Collection (Manassas, VA, USA). The cells were maintained in humidified air at $37^{\circ} \mathrm{C}$, and $5 \% \mathrm{CO}_{2}$ in Dulbecco's modified Eagle's medium (DMEM) containing $100 \mathrm{U} / \mathrm{ml}$ penicillin and streptomycin, and $10 \%$ fetal bovine serum. All materials required for the cell culture were purchased from WelGENE Inc. (Daegu, Republic of Korea). tCA and LPS were purchased from Sigma-Aldrich Chemical Co. (St. Louis, MO, USA). They were dissolved in dimethyl sulfoxide (DMSO, 
Sigma-Aldrich Chemical Co.) and distilled water to make the stock solutions, respectively. Each stock solution (tCA $1 \mathrm{mM}$, LPS $100 \mathrm{mg} / \mathrm{ml}$ ) was appropriately diluted in the complete culture medium and used to treat $\mathrm{C} 2 \mathrm{C} 12$ cells.

\section{Cell viability assay}

The cytotoxicity of tCA against $\mathrm{C} 2 \mathrm{C} 12$ cells in the presence or absence of LPS was determined using the 3-(4,5-dimethylthiazol-2-yl)-2,5-diphenyltetrazolium bromide (MTT) reduction assay. In brief, the cells were seeded into 96-well culture plates at a density of $1 \times 10^{4}$ cells $/ \mathrm{ml}$. After cultivation for $24 \mathrm{~h}$, cells were treated with various concentrations of tCA alone or pre-treated with the indicated concentrations of tCA for $1 \mathrm{~h}$ before $1 \mathrm{mg} / \mathrm{ml}$ LPS treatment for $24 \mathrm{~h}$. Then, the medium was removed, and MTT solution (0.5 $\mathrm{mg} / \mathrm{ml}$, Sigma-Aldrich Chemical Co.) was dispensed into each well and reacted at $37^{\circ} \mathrm{C}$ as previously described [35]. After $3 \mathrm{~h}$, the supernatant was removed and DMSO was added to dissolve the blue formazan crystals for $10 \mathrm{~min}$. The absorbance per well was quantified at a wavelength of $540 \mathrm{~nm}$ using an enzyme-linked immunosorbent assay (ELISA) plate reader (Dynatech Laboratories, Chantilly, VA, USA).

\section{Measurement of NO, PGE2, and cytokines}

The cells were incubated in 24-well culture plates at a density of $5 \times 10^{4}$ cells $/ \mathrm{ml}$ for $24 \mathrm{~h}$, followed by treated with $10 \mathrm{mM}$ or $20 \mathrm{mM}$ tCA for $1 \mathrm{~h}$ and then stimulated with $1 \mathrm{mg} / \mathrm{ml}$ LPS for $24 \mathrm{~h}$. The NO level in the medium was evaluated by the amount of nitrite measured using the Griess reagent (Sigma-Aldrich Chemical Co.) as previously described [36]. Briefly, $100 \mu \mathrm{L}$ of the cell-conditioned medium was mixed with the same amount of Griess reagent for $10 \mathrm{~min}$. The absorbance was measured at $540 \mathrm{~nm}$ using an ELISA reader and calculated by comparison to a sodium nitrite $\left(\mathrm{NaNO}_{2}\right)$ standard curve. To investigate the $\mathrm{PGE}_{2}$ and cytokine levels, the culture supernatants were collected and assayed using commercially available ELISA kits (R\&D Systems Inc., Minneapolis, MN, USA) according to the instructions from the manufacturer. The absorbance was measured at a wavelength of $450 \mathrm{~nm}$ using an ELISA reader as previously described [36].

\section{Reverse transcription-polymerase chain reaction (RT-PCR) assay}

The cells were incubated in 6-well culture plates at a density of $3 \times 10^{5}$ cells $/ \mathrm{ml}$ for $24 \mathrm{~h}$, followed by treated with $10 \mathrm{mM}$ or $20 \mathrm{mM}$ tCA for $1 \mathrm{~h}$ and then stimulated with $1 \mathrm{mg} / \mathrm{ml}$ LPS for $24 \mathrm{~h}$. Total RNA was isolated from the cells using TRIzol reagent (Invitrogen Life Technologies, Carlsbad, CA, USA), following the manufacturer's instructions, and quantified. The isolated total RNA $(1 \mu \mathrm{g})$ was used to synthesize cDNA using AccuPower ${ }^{\circledR}$ RT PreMix (Bioneer, Daejeon, Republic of Korea) according to the manufacturer's instructions. The cDNA generated at room temperature (RT) was amplified using the One-Step RT-PCR PreMix Kit with selected primers (iNtRON Biotechnology Inc., Seongnam, Republic of Korea). Information on the primers used is provided in Table 1. The amplified DNA products were electrophoresed on $1.5 \%$ agarose gels and visualized after ethidium bromide (EtBr, Sigma-Aldrich Chemical Co.) staining as previously described [37]. Densitometric analysis of the bands was performed using the Image ${ }^{\circledR}$ software (v1.48, NIH, Bethesda, MD).

Table 1. Primer information for RT-RCR.

\begin{tabular}{lll}
\hline Gene & Forward sequence & Reverse sequence \\
\hline COX-2 & GCGACATACTCAAGCAGGA & AGTGGTAACCGCTCAGGTGTT \\
& GCA & G \\
iNOS & GAGACAGGGAAGTCTGAAG & CCAGCAGTAGTTGCTCCTCTT \\
& CAC & C \\
IL-6 & TACCACTTCACAAGTCGGAG & CTGCAAGTGCATCATCGTTGT \\
& GC & TC \\
TNF- $\alpha$ & GGTGCCTATGTCTCAGCCTCT & GCCATAGAACTGATGAGAGG \\
& T & GAG \\
GAPD & CATCACTGCCACCCAGAAGA & ATGCCAGTGAGCTTCCCGTTC \\
H & CTG & A \\
\hline
\end{tabular}

\section{Protein isolation and Western blot analysis}

The cells were incubated in $100 \mathrm{~mm}$ culture dish at a density of $2 \times 10^{6}$ cells $/ \mathrm{ml}$ for $24 \mathrm{~h}$, followed by treated with $10 \mathrm{mM}$ or $20 \mathrm{mM}$ tCA for $1 \mathrm{~h}$ and then stimulated with $1 \mathrm{mg} / \mathrm{ml}$ LPS for $24 \mathrm{~h}$. To extract proteins, the cells were washed with cold phosphate-buffered saline (PBS) and lysed with lysis buffer as previously described [38]. In parallel, nuclear extraction reagents (Thermo Fisher Scientific, Waltham, MA, USA) were used to isolate proteins from the nucleus and cytoplasm according to the manufacturer's protocol. The concentration of the isolated protein was measured using the Bio-Rad protein assay kit obtained from Bio-Rad Laboratories (Hercules, CA, USA). Equal amounts of protein were separated by $8 \% \sim 15 \%$ sodium dodecyl sulfate-polyacrylamide gel electrophoresis. Proteins in the gel were subsequently transferred to polyvinylidene difluoride membranes (Schleicher and Schuell GmbH, Keene, NH, USA). The protein-transferred membranes were blocked with non-fat dry milk solution (5\%) at RT for $1 \mathrm{~h}$, and then reacted with primary anti-bodies $(1: 1,000)$ obtained from Santa Cruz Biotechnology, Inc. (Santa Cruz, CA, USA) and Cell Signaling Technology (Beverly, MA, USA) overnight at $4^{\circ} \mathrm{C}$. The membranes were washed three times for $5 \mathrm{~min}$ with Tris-buffered saline $(0.1 \%$ 
Tween-20) and then incubated with goat anti-rabbit IgG-horseradish-peroxidase (HRP) and goat anti-mouse IgG-HRP secondary antibodies (1:10,000; Santa Cruz Biotechnology, Inc.) for $2 \mathrm{~h}$ at RT. The membrane was reacted with an enhanced chemiluminescent solution purchased from Amersham Corp. (Arlington Heights, IL, USA) and then exposed to X-ray film to visualize the corresponding proteins. Densitometric analysis of the bands was performed using the Image ${ }^{\circledR}$ software (v1.48, NIH, Bethesda, MD).

\section{Immunofluorescence for NF-KB}

C2C12 cells were seeded into 4-well cell culture slides at a density of $5 \times 10^{4}$ cells $/ \mathrm{ml}$ and stabilized for $24 \mathrm{~h}$. The cells were pre-treated with $20 \mathrm{mM}$ tCA for 1 $\mathrm{h}$ and then treated with or without $1 \mathrm{mg} / \mathrm{ml}$ LPS for 1 h. After treatment, the cells were fixed with ice-cold methanol for $10 \mathrm{~min}$ and washed with PBS. Subsequently, the cells were blocked using $5 \%$ bovine serum albumin (BSA, Sigma-Aldrich Chemical Co.) with PBS-T (PBS containing 0.1\% Triton $\mathrm{X}$ ) for $1 \mathrm{~h}$ and then incubated with anti-NF-kB p65 (1:100 in 2.5\% BSA in PBS-T) at $4^{\circ} \mathrm{C}$ overnight. The cells were washed with PBS-T and incubated with the secondary antibody (goat anti-rabbit IgG cross-absorbed secondary antibody conjugated to Alexa Fluor (AF) 594, Thermo Fisher Scientific) for $1 \mathrm{~h}$. After washing with PBS, the cells were counterstained with 4',6-diamidino-2-phenylindole (DAPI, Sigma-Aldrich Chemical Co.) for $20 \mathrm{~min}$. Cell fluorescence was observed using a fluorescence microscope (Carl Zeiss, Oberkochen, Germany) at Core-Facility Center for Tissue Regeneration (Dong-eui University, (Busan, Republic of Korea).

\section{Measurement of LPS binding levels on cell surface}

C2C12 cells were seeded into 4 -well cell culture slides at a density of $5 \times 10^{4}$ cells $/ \mathrm{ml}$ and stabilized for $24 \mathrm{~h}$. To explore the inhibitory effect of tCA on TLR4 expression on the cell surface of $\mathrm{C} 2 \mathrm{C} 12$ cells, the cells pre-treated with $20 \mu \mathrm{M}$ tCA for $1 \mathrm{~h}$ were further treated with $1 \mu \mathrm{g} / \mathrm{ml}$ AF 488-conjugated LPS (Molecular Probes Inc., Leiden, Netherlands) for $1 \mathrm{~h}$. After the reaction was over, the cells were fixed in $3.7 \%$ paraformaldehyde, washed with PBS, and then analyzed at $494 \mathrm{~nm} / 517 \mathrm{~nm}$ with flow cytometry as previously described [39].

\section{Immunofluorescence staining for formation of LPS/TLR4 complexes}

To analyze the formation of LPS/TLR4 complexes on the cell surface, $\mathrm{C} 2 \mathrm{C} 12$ cells were seeded into 4-well cell culture slides at a density of
$5 \times 10^{4}$ cells $/ \mathrm{ml}$ and stabilized for $24 \mathrm{~h}$ and pre-treated with $20 \mu \mathrm{M}$ tCA for $1 \mathrm{~h}$ and then treated with or without $1 \mu \mathrm{g} / \mathrm{ml}$ AF 488-conjugated LPS as previously described [40]. The cells were fixed in 3.7\% paraformaldehyde for $10 \mathrm{~min}$, stained with anti-TLR4 antibody for $90 \mathrm{~min}$ at $4^{\circ} \mathrm{C}$, and then incubated with AF 594-conjugated secondary antibody at RT for $1 \mathrm{~h}$. After washing with PBS, the cells were also counterstained with DAPI solution for $20 \mathrm{~min}$. Cell fluorescence of LPS/TLR4 complex was observed at $590 \mathrm{~nm} / 617 \mathrm{~nm}$ using a fluorescence microscope. In addition, fluorescence intensity of DAPI-stained nuclear was recorded at $358 \mathrm{~nm} / 461 \mathrm{~nm}$ by a fluorescence microscope.

\section{Measurement of ROS levels}

ROS was measured using 5,6-carboxy-2', $7^{\prime}-$ dichlorofluorescein diacetate (DCF-DA, SigmaAldrich Chemical Co.). Briefly, C2C12 cells were incubated in 6-well culture plates at a density of $3 \times 10^{5}$ cells $/ \mathrm{ml}$ for $24 \mathrm{~h}$, and pre-treated with $20 \mu \mathrm{M}$ tCA for $1 \mathrm{~h}$ and then incubated for $1 \mathrm{~h}$ in the absence or presence of $1 \mu \mathrm{g} / \mathrm{ml}$ LPS. The cells were stained with $10 \mu \mathrm{M}$ DCF-DA for $15 \mathrm{~min}$ in the dark at $37^{\circ} \mathrm{C}$. The cells were then washed with PBS and immediately recorded at $480 \mathrm{~nm} / 520 \mathrm{~nm}$ by flow cytometry (BD Biosciences, San Jose, CA, USA) as previously described [41]. To compare the degree of ROS generation through fluorescence microscopic observation, the cells were stained with DCF-DA for $15 \mathrm{~min}$ at $37^{\circ} \mathrm{C}$ and then fixed with $3.7 \%$ paraformaldehyde for $10 \mathrm{~min}$. The cells were washed with PBS and analyzed for ROS fluorescence intensity using a fluorescence microscope.

\section{Zebrafish maintenance and LPS microinjection}

AB strain zebrafish, which were provided by Dr. $\mathrm{CH}$ Kang (Nakdong National Institute of Biological Resources, Sangju, Republic of Korea) were maintained at $28.5^{\circ} \mathrm{C}$ with a $14 / 10 \mathrm{~h}$ light/dark cycle according to the standard guidelines of the Animal Care and Use Committee of Jeju National University (Approval No.: 2019-0053, Jeju, Republic of Korea). Fertilized embryos were collected after natural spawning as previously described [42] and cultured in $2 \mathrm{mg} / \mathrm{L}$ methylene blue containing E3 embryo media at $28.5^{\circ} \mathrm{C}$. Three days post-fertilized (dpf) zebrafish larvae were anesthetized using $0.04 \%$ tricaine (Sigma-Aldrich Chemical Co.) and LPS $(0.5 \mathrm{mg} / \mathrm{mL}, 2$ $\mathrm{nL}$ in each larva) was microinjected into the yolk using a Drummond NANOJECT III injector (Drummond Scientific, Broomall, PA, USA). The negative control group was injected with PBS. The larvae were washed three times after LPS 
microinjection and immediately placed in E3 media containing the indicated concentrations of tCA. Each group of larvae $(n=20)$ was cultured at $28.5^{\circ} \mathrm{C}$ for $24 \mathrm{~h}$.

\section{NO and ROS staining in zebrafish larvae}

The production of $\mathrm{NO}$ and ROS in zebrafish larvae was visualized using 4-amino-5-methylamino2'7'-difluorofluorescein diacetate (DAF-FM-DA, Sigma-Aldrich Chemical Co.) and DCF-DA, respectively, $24 \mathrm{~h}$ after treatment as previously described [42]. In brief, zebrafish embryos (4 dpf) were transferred to 24-well plates and incubated with $5 \mu \mathrm{M}$ DAF-FM-DA and $20 \mu \mathrm{M}$ DCF-DA for $30 \mathrm{~min}$ and visualized using the CELENA ${ }^{\circledR}$ S Digital Imaging System (Logos Biosystems, Anyang, Gyeonggido, Republic of Korea). Fluorescence intensities were calculated using ImageJ software (Wayne Rasband, National Institute of Health, Bethesda, MD, USA) and expressed as a percentage compared to the untreated control.

\section{Statistical analysis}

The data were analyzed with GraphPad Prism software (GraphPad Software, Inc., La Jolla, CA, USA) using one-way analysis of variance (ANOVA) for multiple comparisons, followed by Tukey's post hoc test. All numerical data are presented as the mean \pm standard deviation (SD) of at least triplicate experiments. P-values of less than 0.05 were considered statistically significant.

\section{A)}

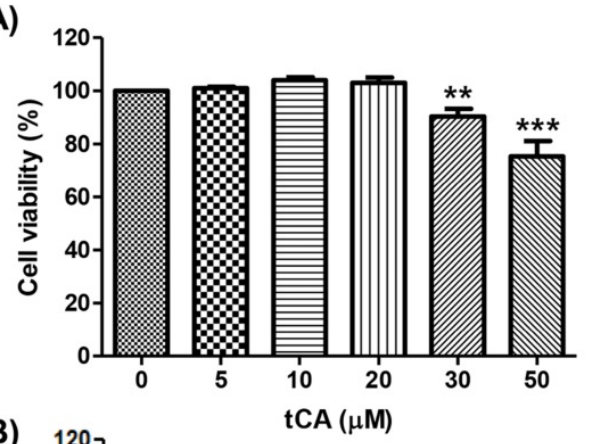

B)

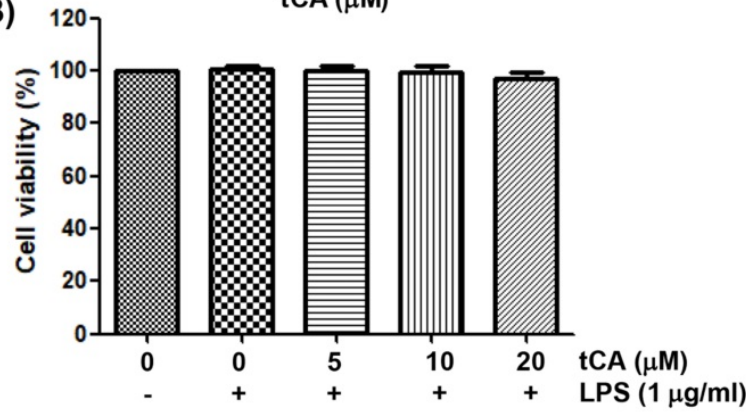

Figure 1. Effect of tCA and LPS on the cell viability of C2C12 myoblasts. Cells were treated with different concentrations of tCA alone for $24 \mathrm{~h}(\mathrm{~A})$ or pre-treated with or without the indicated concentrations of tCA for $1 \mathrm{~h}$ before 1 $\mathrm{mg} / \mathrm{ml}$ LPS stimulation for $24 \mathrm{~h}$ (B). Cell viability was analyzed using the MTT assay. Data indicate the mean $\pm S D$ of three independent experiments. Significant differences among the groups were determined $\left(* * 0.01\right.$ and ${ }^{* * * *} p<0.001$, compared with the control cells).

\section{Results}

\section{Effect of tCA on the proliferation of $\mathrm{C} 2 \mathrm{C} 12$ myoblasts}

The cytotoxic effect of tCA on C2C12 myoblasts was determined by the MTT assay. As shown in Figure 1A, at concentrations below $20 \mu \mathrm{M}$, tCA was not cytotoxic to $\mathrm{C} 2 \mathrm{C} 12$ cells, but significant cytotoxicity was observed in cells treated with $30 \mu \mathrm{M}$ or more. Subsequent experiment did not show any adverse effect on cell viability when $20 \mu \mathrm{M}$ or less tCA was administered to $1 \mu \mathrm{g} / \mathrm{ml}$ LPS-treated C2C12 cells (Figure 1B).

\section{tCA reduces LPS-induced $N O$ and $P G_{2}$ production in $\mathrm{C} 2 \mathrm{C} 12$ myoblasts}

To evaluate the anti-inflammatory effects of tCA, the levels of inflammatory mediators such as $\mathrm{NO}$ and $\mathrm{PGE}_{2}$ in the culture supernatant were detected. As shown in Figures 2A and B, LPS stimulation markedly increased the release of $\mathrm{NO}$ and $\mathrm{PGE}_{2}$ compared to the unstimulated control, but this increase was significantly reduced in tCA-pre-treated cells in a concentration-dependent manner. Next, we investigated whether tCA could inhibit the expression of iNOS and COX-2 by LPS. According to the Western blotting and RT-PCR results, the protein and mRNA expression of iNOS and COX-2 increased by LPS was significantly suppressed in the presence of tCA (Figures 2C-F).

\section{tCA inhibits the production and expression of LPS-induced pro-inflammatory cytokines in C2C12 myoblasts}

Next, we investigated the effect of tCA on the production and expression of pro-inflammatory cytokines increased by LPS treatment. Our results showed that the amount of pro-inflammatory cytokines, including TNF- $\alpha$ and IL-6, released into the culture supernatant after stimulation with LPS increased significantly. However, the enhanced production of these cytokines by LPS was significantly suppressed by tCA pre-treatment, and this effect was dependent upon the tCA treatment concentration (Figures $3 \mathrm{~A}$ and B). Subsequently, whether the inhibition of cytokine production by tCA in LPS-treated $\mathrm{C} 2 \mathrm{C} 12$ cells was associated with the decreased expression of these genes was also investigated. As a result, LPS treatment significantly increased the expression of the two cytokine proteins, but their expression was reduced in cells pre-treated with tCA (Figures 3C-F). 
A)

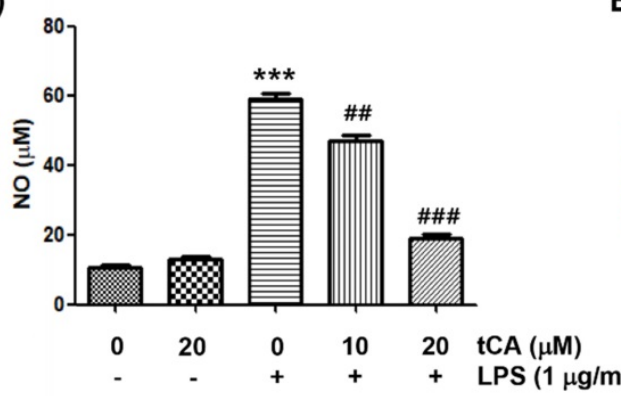

C)

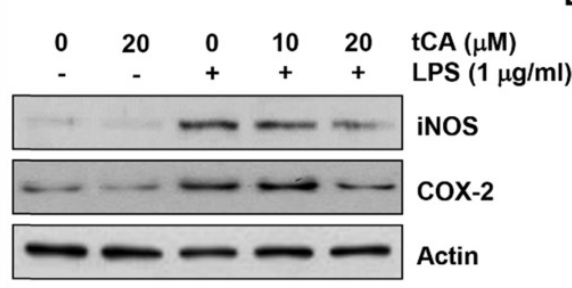

E)

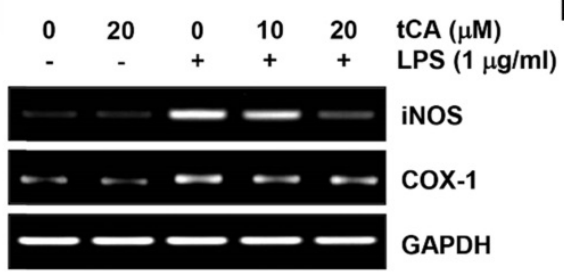

B)

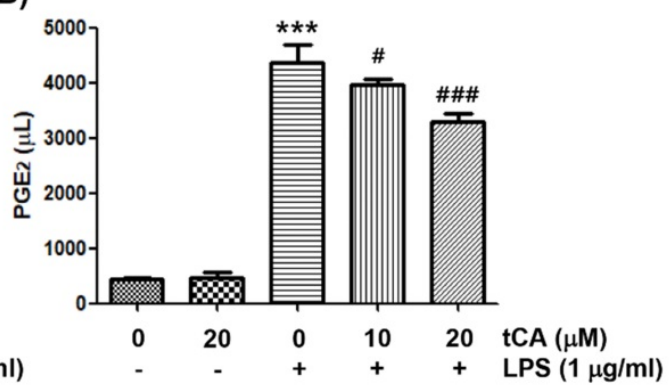

D)
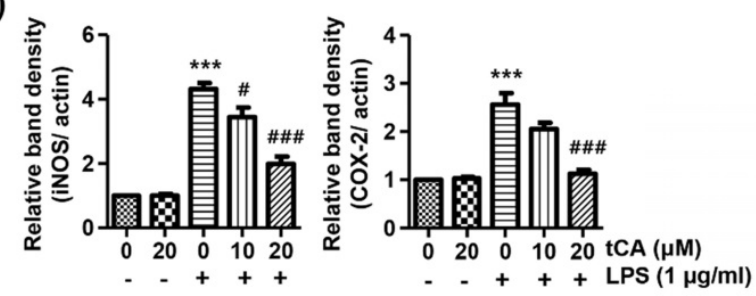

F)
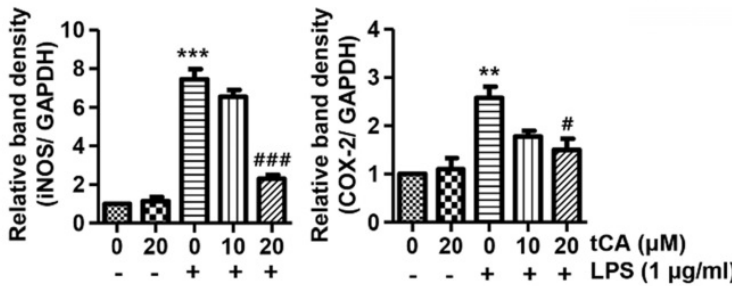

Figure 2. Inhibitory effect of tCA on the production of pro-inflammatory mediators in LPS-treated C2C12 myoblasts. Cells were treated with the indicated concentrations of tCA for $1 \mathrm{~h}$ and then stimulated with $1 \mathrm{mg} / \mathrm{ml}$ LPS for $24 \mathrm{~h}$. (A and B) The levels of NO (A), and PGE 2 (B) in the culture medium were determined by the Griess reaction and a commercial PGE $E_{2}$ ELISA kit. The absorbance was measured using a microplate reader. The error bars represent the SD of three independent experiments $(* * *$

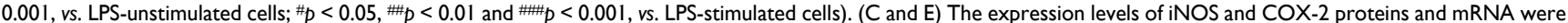
measured by Western blot analysis and RT-PCR, respectively. Actin and glyceraldehyde-3-phosphate dehydrogenase (GAPDH) were used as internal controls for the Western blot analysis and RT-PCR, respectively. (D and F) Relative band density. Data are expressed as the mean $\pm S D\left({ }^{* *} p<0.01\right.$ and ${ }^{* * * *} p<0.001, v s$. LPS-unstimulated cells; $\#<0.05$ and \# $<0.001$, vs. LPS-stimulated cells).

\section{tCA suppresses the nuclear translocation of NF-KB in LPS-stimulated C2C12 myoblasts}

It was further investigated whether tCA inhibits the LPS-mediated activation of NF-kB because it is a key factor controlling the transcription of pro-inflammatory mediators and cytokines. When C2C12 cells were stimulated with LPS, the expression of NF-KB in the nucleus and phosphorylated IKB kinase (p-IKK)-a/b was significantly increased compared with the control group (Figures 4A-D). By contrast, the level of IKB- $\alpha$ in the cytoplasm was decreased by the treatment of LPS, indicating that NF-KB was activated. However, tCA reduced the nuclear accumulation of NF- $\mathrm{kB}$ p65, the degradation of IKB-a and the expression of $\mathrm{p}-\mathrm{IKK}-\mathrm{a} / \mathrm{b}$ induced by LPS. Consistent with the immunoblotting results, the increase in fluorescence intensity of NF- $\mathrm{kB}$ p65 observed in the nuclei of LPS-treated cells was markedly decreased by pre-treatment with tCA, as shown in Figure 4E.

\section{tCA diminishes the activation of the TLR4/myeloid differentiation factor 88 (MyD88) pathway induced by LPS in $\mathrm{C2C12}$ myoblasts}

Since LPS binds to TLR4, leading to the activation of the NF-kB signaling pathway through a Myd88-dependent and/or independent manner, we investigated the effect of tCA on the expression of TLR4 and Myd88 in LPS-treated C2C12 cells. As shown in Figures 5A and B, LPS treatment highly up-regulated the expression of TLR4 and MyD88, which was significantly reduced in the presence of tCA. In addition, it was confirmed by flow cytometry analysis that the level of AF 488-conjugated LPS bound to the cell surface was significantly reduced in tCA-pre-treated cells compared to untreated cells (Figures 5C and D). Therefore, we evaluated whether tCA could inhibit LPS binding to TLR4 in the outer membrane of $\mathrm{C} 2 \mathrm{C} 12$ cells. The results showed that the fluorescence intensity of LPS and TLR4 was strongly observed outside the cell membrane after LPS intervention. However, their fluorescence intensity was significantly weakened in the presence of tCA (Figure 5E). 
A)

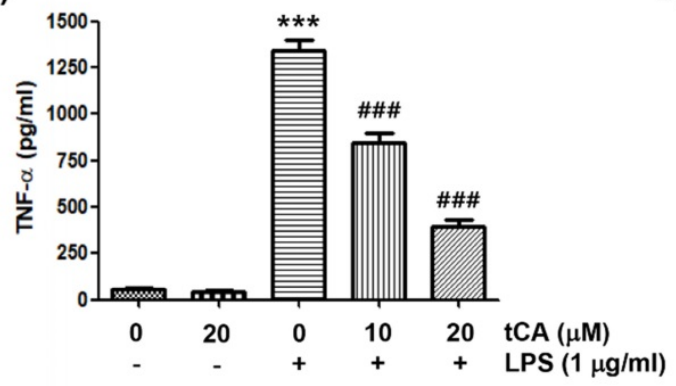

B)

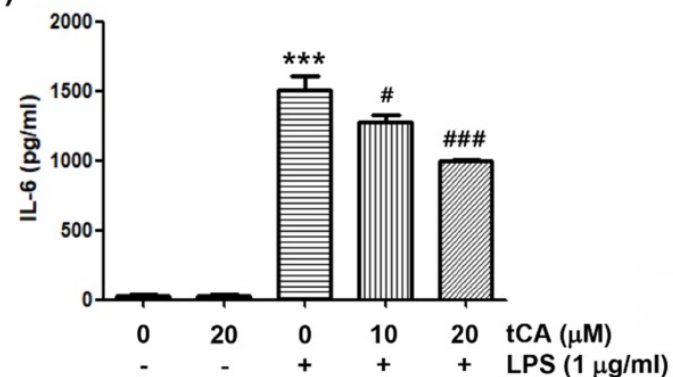

C)

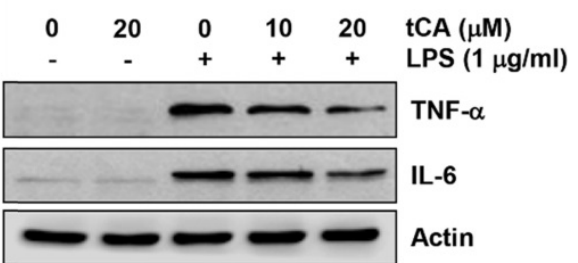

E)

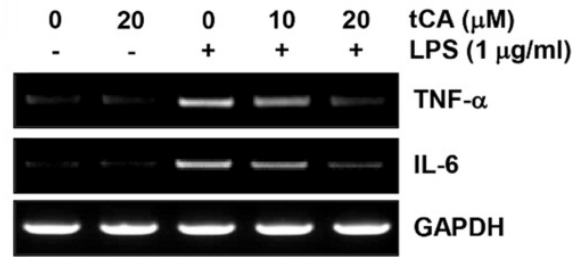

D)
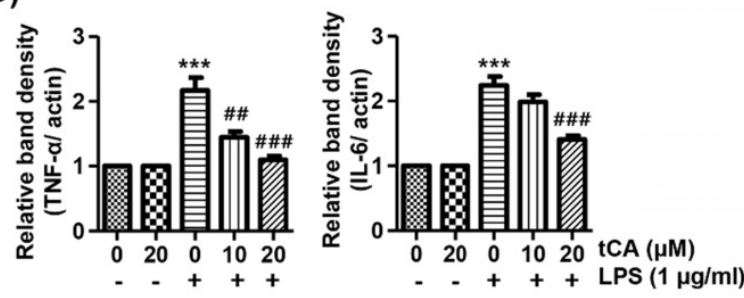

F)

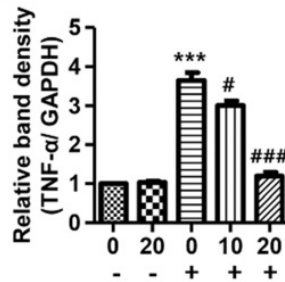

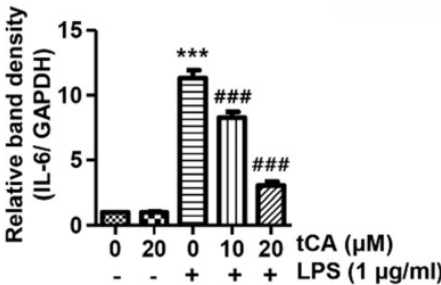

Figure 3. Inhibitory effect of tCA on the production of pro-inflammatory cytokines in LPS-treated C2C12 myoblasts. Cells were treated with the indicated concentrations of tCA for $1 \mathrm{~h}$ and then stimulated with $1 \mathrm{mg} / \mathrm{ml}$ LPS for $24 \mathrm{~h}$. (A and B) The levels of TNF- $\alpha$ (A), and IL-6 (B) in the culture medium were measured using commercial ELISA kits. The absorbance was measured using a microplate reader. The error bars represent the SD of three independent experiments (*** $<<0.001$, vs. LPS-unstimulated cells; $\# p<0.05$ and ${ }^{\# \# p}<0.001$, vs. LPS-stimulated cells). (C and E) The expression levels of TNF- $\alpha$ and IL-6 proteins and mRNA were measured by Western blot analysis and RT-PCR, respectively. Actin and GAPDH were used as internal controls for the Western blot analysis and RT-PCR, respectively. (D and F) Relative band density. Data are expressed as the mean \pm SD $\left(* * p<0.001\right.$, vs. LPS-unstimulated cells; $\# p<0.05$, \# $p<0.01$ and $\#^{*} p<0.001$, vs. LPS-stimulated cells).

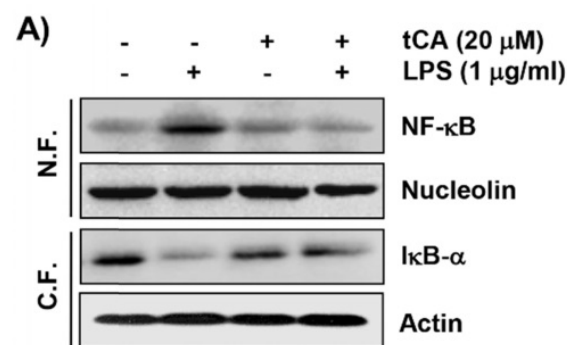

C)

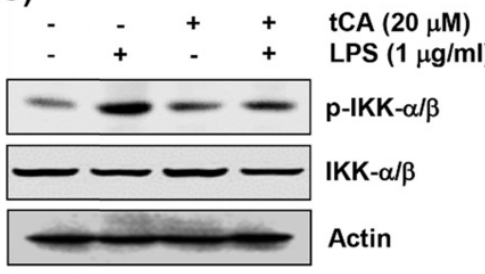

D)
B)
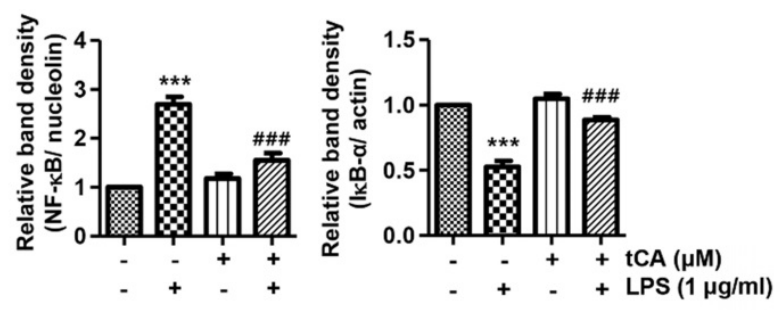

E)
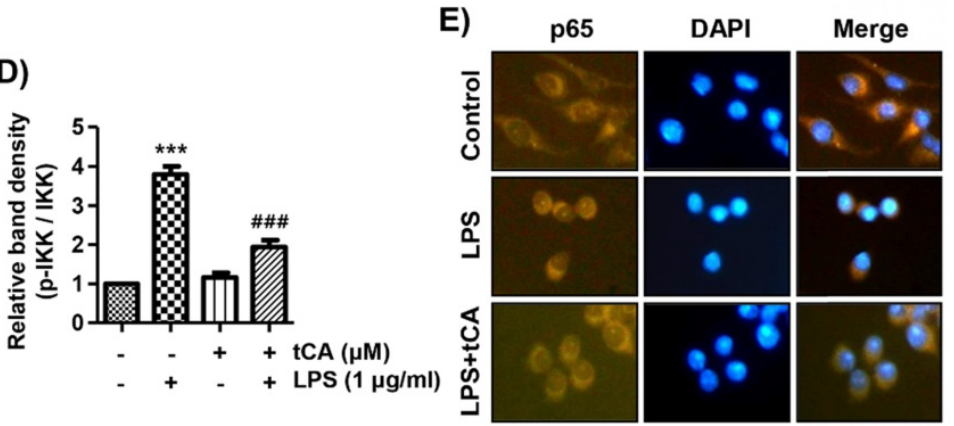

Figure 4. Inhibition of LPS-induced activation of NF-KB signaling pathway by tCA in C2C12 myoblasts. Cells were treated with 20 mM tCA alone for $24 \mathrm{~h}$ or pre-treated with or without $20 \mathrm{mM}$ tCA for $1 \mathrm{~h}$ before $1 \mathrm{mg} / \mathrm{ml}$ LPS stimulation for $1 \mathrm{~h}$. (A) For Western blot analysis, nuclear and cytosolic proteins were isolated, and the expression of NF-KB and IKB-a was investigated. Protein loading was confirmed by the analysis of nucleolin or actin expression in each protein extract. N.F., nuclear fraction; C.F., cytosolic fraction. (C) The expression levels of $\mathrm{p}-\mathrm{IKK}-\mathrm{a} / \mathrm{b}$ and IKK-a/b proteins were measured by Western blot analysis using total protein. (B and D) Relative band density. Data are expressed as the mean \pm SD ( ${ }^{* * * *} p<0.001$, vs. LPS-unstimulated cells; \#埥 $p<0.001$, vs. LPS-stimulated cells). (E) The cells were subjected to immunofluorescence staining with NF-KB p 65 antibody and representative fluorescence images were acquired using a fluorescence microscope. Brown fluorescence indicates the localization of NF-KB p 65 and blue fluorescence by DAPI staining allows visualization of the nuclei. 
A)

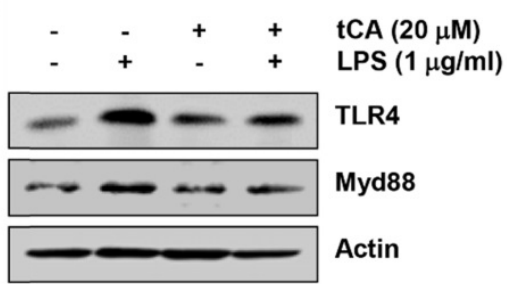

B)

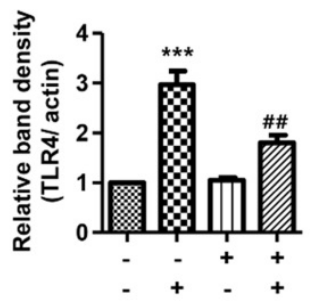

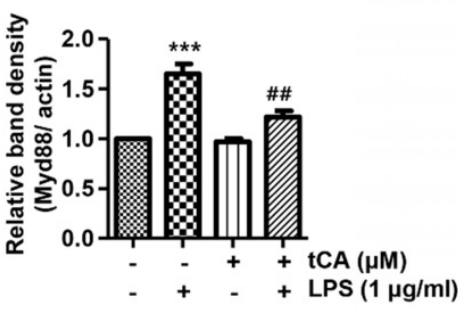

E)

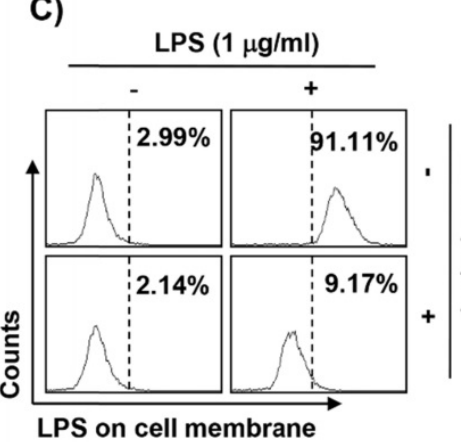

D)

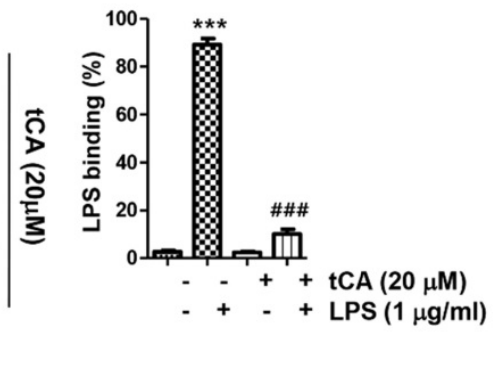

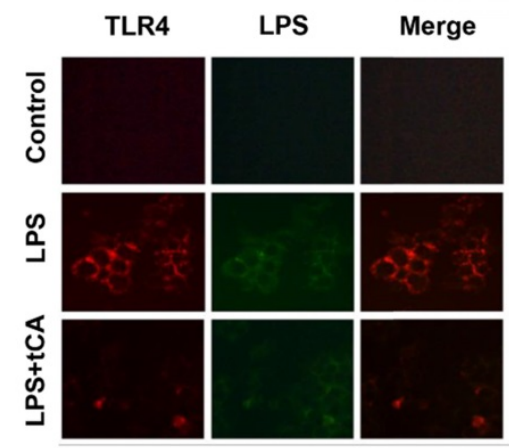

Figure 5. Inhibitory effects of tCA on TLR4 and Myd88 expression and interaction between LPS and TLR4 in LPS-treated C2C12 myoblasts. (A) Cells were pre-treated with $20 \mathrm{mM}$ tCA for $1 \mathrm{~h}$ prior to $1 \mathrm{mg} / \mathrm{ml}$ LPS treatment for $6 \mathrm{~h}$. The protein levels of TLR4 and Myd88 were determined by Western blot analysis. Actin was used as an internal control. (B) Relative band density. Data are expressed as the mean \pm SD ${ }^{* * * *} p<0.001$, vs. LPS-unstimulated cells; \#p $<0.01$, vs. LPS-stimulated cells). (C-E) Cells were treated with $20 \mathrm{mM}$ tCA alone for $1 \mathrm{~h}$ or pre-treated with or without $20 \mathrm{mM}$ tCA for $1 \mathrm{~h}$ before $1 \mathrm{mg} / \mathrm{ml}$ AF 488 -conjugated LPS stimulation for 30 min. (C and D) The level of binding of LPS to the cell surface was measured by flow cytometry. (C) The images shown represent representative plots of three replicate experiments. (D) The

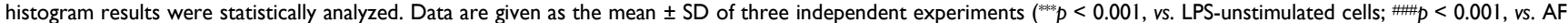
488-conjugated LPS-stimulated cells). (E) The distribution of TLR4 (green) and AF 488-conjugated LPS (red) was detected by a fluorescence microscope. Experiments were repeated three times and representative fluorescence micrographs were presented.

\section{tCA alleviates LPS-mediated generation of ROS in C2C12 myoblasts}

Because oxidative stress also plays an important role in the inflammatory response, we investigated whether tCA could inhibit LPS-induced oxidative stress. The flow cytometry results using the DCF-DA probe showed that the increase in ROS content in C2C12 cells treated with LPS was dramatically reduced by the addition of $\mathrm{tCA}$ (Figures $6 \mathrm{~A}$ and $\mathrm{B}$ ). Consistent with the results from the flow cytometry, the increase in the fluorescence intensity of DCF-DA observed in the cells treated with LPS was also weakened by pretreatment of tCA (Figure 6C).

\section{tCA activates the Nrf2/HO-1 signaling pathway, but inhibits NADPH oxidases (NOXs) expression in $\mathrm{C} 2 \mathrm{C} 12$ myoblasts}

We next investigated whether the inhibitory effect of tCA on oxidative stress by LPS was related to the Nrf2/HO-1 and NOXs signaling pathways. According to the results of the Western blot analysis, the expression of Nrf2 and HO-1 was slightly increased by tCA treatment in $\mathrm{C} 2 \mathrm{C} 12$ cells, which was associated with an increased expression of phosphorylated Nrf2 (p-Nrf2) (Figures 6D and E). However, their expression in cells co-treated with LPS and tCA was much higher than that of LPS and tCA alone treatment. On the other hand, the expression of
NOX family proteins including NOX1 and NOX2, which was increased by LPS stimulation, remained at the control level in the presence of tCA.

\section{tCA weakens the production of NO and ROS in LPS-treated zebrafish larvae}

As tCA downregulates inflammatory and oxidative responses in $\mathrm{C} 2 \mathrm{C} 12$ cells, we wondered if tCA had a similar effect in the in vivo model and demonstrated it using the zebrafish model. According to the results of DAF-FM-DA staining, LPS microinjection significantly increased NO generation. However, in the presence of tCA within a non-toxic range, the LPS-induced NO generation gradually decreased in a concentration-dependent manner (Figures 7A and B). In addition, we confirmed by DCF-DA staining that the increased ROS accumulation in LPS-microinjected zebrafish larvae was dose-dependently abrogated in the presence of tCA (Figures 7C and D).

\section{Discussion}

To evaluate the anti-inflammatory efficacy of $\mathrm{tCA}$, we first investigated the effect of $\mathrm{tCA}$ on the production of $\mathrm{NO}$ and $\mathrm{PGE}_{2}$. Among them, $\mathrm{NO}$ is synthesized from L-arginine by NO synthase, and acts as not only a potent activator but also an inhibitor of the inflammation [43-47]. Several studies suggested that NO plays a critical role in normal physiological 
conditions such as neurotransmission, vasodilation, and immune defense $[43,44]$. Lee et al. demonstrated that NO suppresses LPS-induced inflammation in a mouse asthma model by attenuating the interaction of IKK and heat shock protein 90 [45]. In addition, Raychaudhuri et al. reported that NO blocks LPS-stimulated NF-kB activation in alveolar macrophages [46]. Although the several studies suggested that NO plays a potential inhibitor of the inflammation, the role is restricted in almost bronchial system. In this regard, the role as pro-inflammatory mediator of $\mathrm{NO}$ is still superiority. Excessive NO formation due to increased iNOS expression promotes the inflammatory response and increases oxidative stress and tissue damage [47]. COX enzymes catalyze the conversion of arachidonic acid to prostaglandins, including $\mathrm{PGE}_{2}$, a group of hormone-like substances that participate in various body functions $[8,7]$. However, excessive $\mathrm{PGE}_{2}$ production, promoted by the increased activity of COX-2 following various inflammatory stimuli, also plays an important role as an inflammatory mediator [43,44]. Therefore, inhibitors of the excessive production of these inflammatory mediators can be regarded as therapeutic agents against inflammation-related diseases. Our data indicated that the up-graduated secretion of $\mathrm{NO}$ and $\mathrm{PGE}_{2}$ in LPS-stimulated $\mathrm{C} 2 \mathrm{C} 12$ myoblasts was progressively inhibited at increasing concentrations of tCA, which was associated with inhibition of the expression of iNOS and COX-2 protein and mRNA. These data demonstrated that the anti-inflammatory effect of tCA was at least due to the reduced expression of iNOS and COX-2, which are involved in $\mathrm{NO}$ and $\mathrm{PGE}_{2}$ production, and support the results of previous studies observed in human knee articular chondrocytes, and murine microglial cells $[22,24,27,30]$. Furthermore, the present finding from $\mathrm{C} 2 \mathrm{C} 12$ cells that $\mathrm{tCA}$ suppressed $\mathrm{NO}$ production following by LPS exposure, is accords with the result from zebrafish.

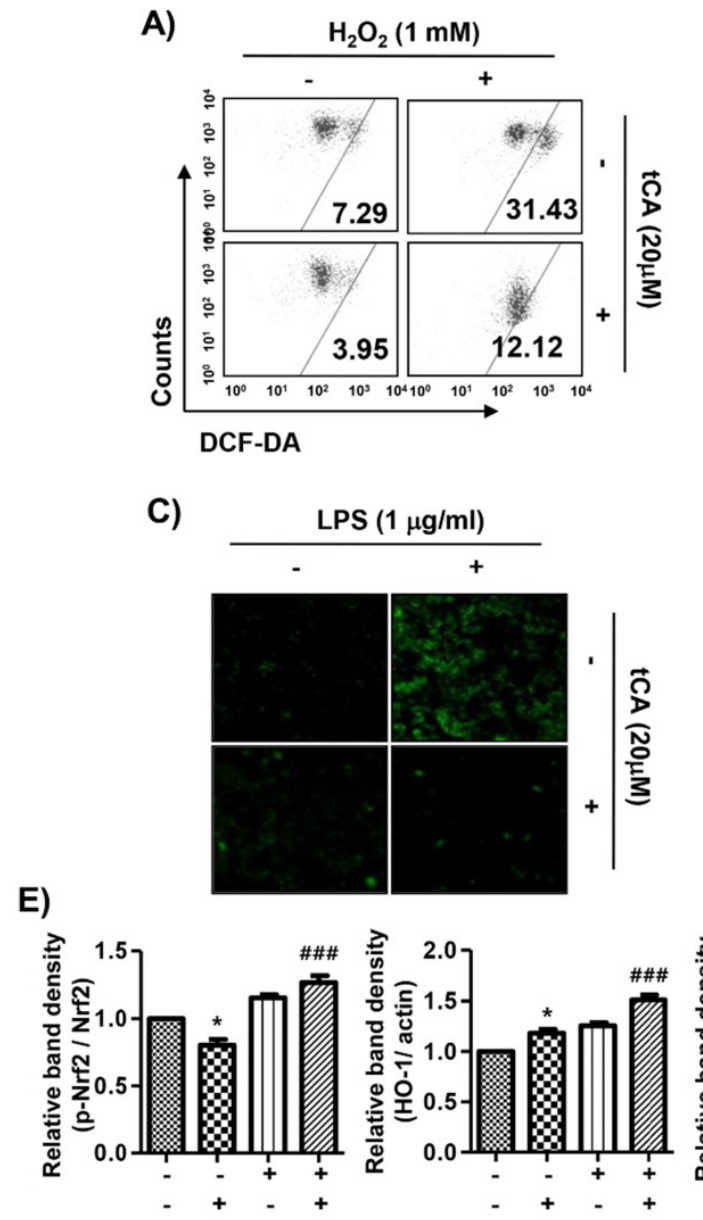

B)

D)
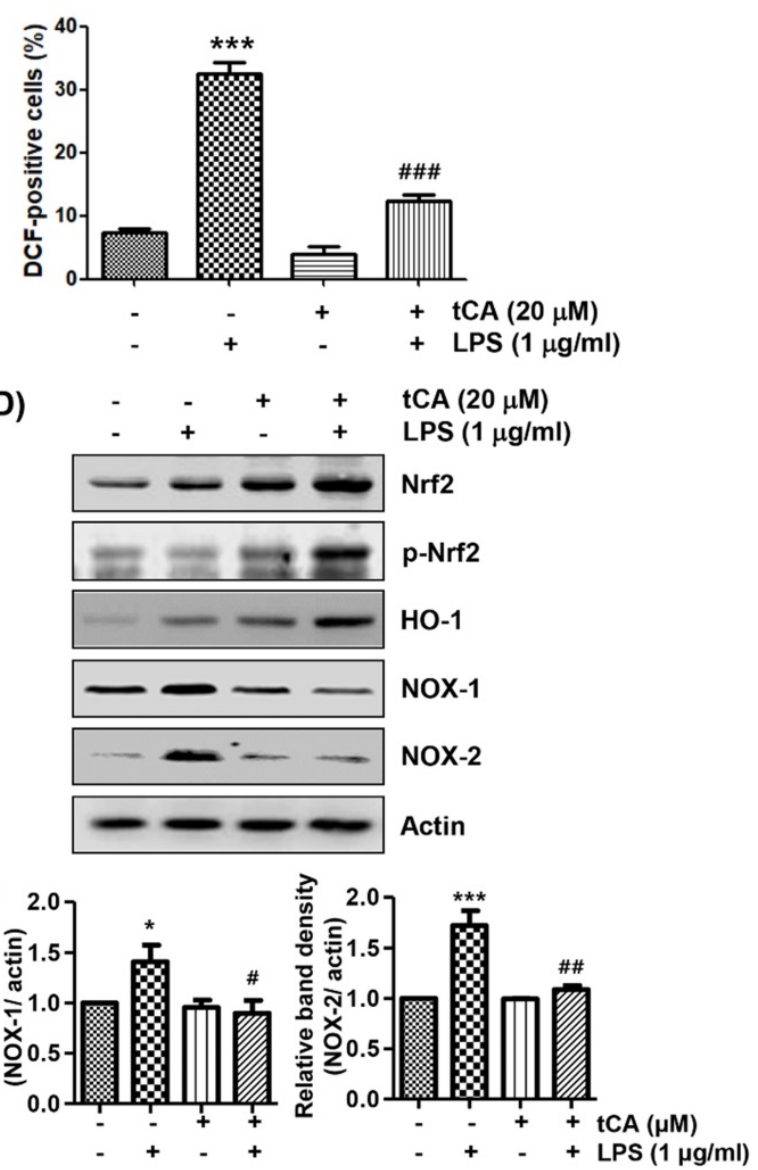

Figure 6. Inhibition of ROS generation, activation of Nrf2/HO-1 signaling pathway, and suppression of NOXs expression by tCA in LPS-stimulated C2C12 myoblasts. Cells were pre-treated with $20 \mathrm{mM}$ tCA for $1 \mathrm{~h}$ and then treated with $1 \mathrm{mg} / \mathrm{ml}$ LPS for $1 \mathrm{~h}$ (A-C) or $24 \mathrm{~h}$ (D). (A) The DCF-DA-stained cells were collected, and then DCF fluorescence was analyzed by flow cytometry. (B) Data are given as the mean \pm SD of three independent experiments (*** $<<0.001$, vs. LPS-unstimulated cells; \# $\quad$ < 0.001 , vs. LPS-stimulated cells). (C) ROS generation was also detected by a fluorescence microscope and representative fluorescence micrographs depicting ROS generation are presented. (D) The expression levels of Nrf2, p-Nrf2, HO-1, and NOXs proteins were measured by Western blot analysis. Protein loading was confirmed by the analysis of actin expression. (E) Relative band density. Data are expressed as the mean \pm SD $\left({ }^{*} p<0.05\right.$ and ${ }^{* *} p<0.001$, vs. LPS-unstimulated cells; \# $p<0.05$, \# $p<0.01$ and \#\# $<<0.001$, vs. LPS-stimulated cells). 
A)

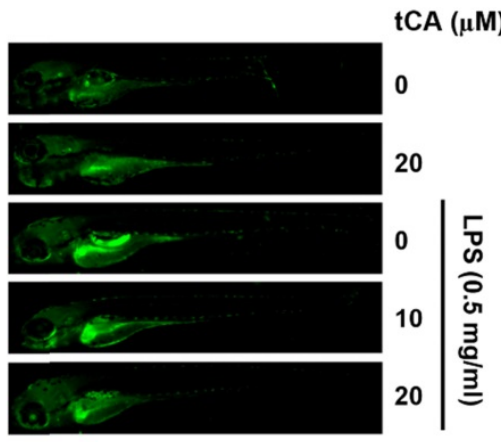

C)

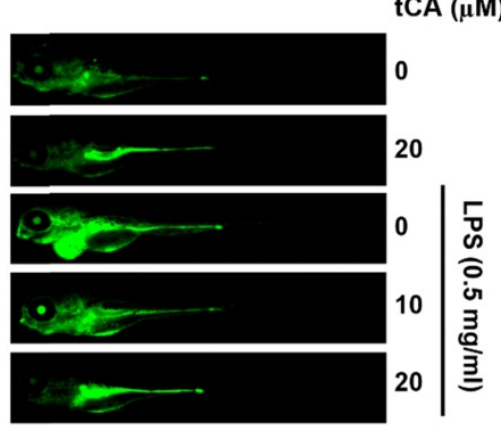

B)

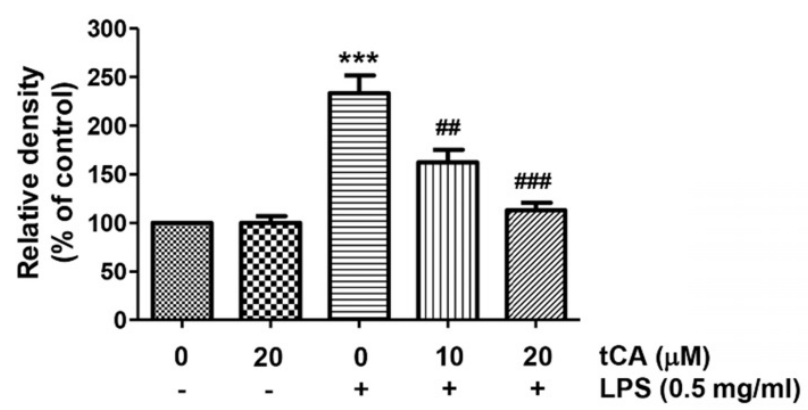

D)

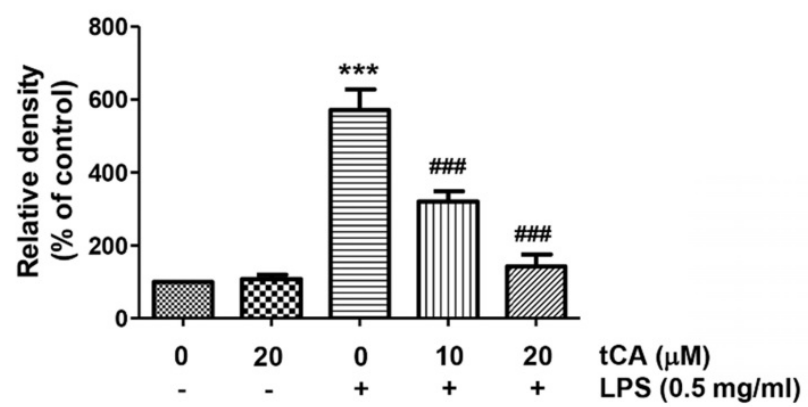

Figure 7. Inhibition of LPS-induced NO and ROS generation by tCA in zebrafish larvae. Zebrafish at $3 \mathrm{dpf}$ were microinjected with $2 \mathrm{~nL}$ of $0.5 \mathrm{mg} / \mathrm{ml}$ LPS and placed in E3 media containing the indicated concentrations of $\mathrm{tCA}$ for $24 \mathrm{~h}$. The larvae were incubated with $5 \mu$ M DAF-FM-DA (A and B) or $20 \mu M$ DCF-DA (C and D) for NO and ROS detection, respectively, and visualized using the CELENA $B$ S Digital Imaging System. (B and D) Relative fluorescence intensities were calculated and expressed compared to the untreated control. Each value indicates the mean \pm SD and is representative of three independent experiments with 10 fish for each group. Significant differences among the groups were determined $\left({ }^{* * * *} p<0.001\right.$, vs. LPS-unstimulated larvae; $p<0.01$ and $\#^{\prime \prime} p<0.001$, vs. LPS-stimulated larvae).

During the inflammatory response, macrophages secrete multiple pro-inflammatory cytokines that are involved in various signaling pathways producing autocrine and/or paracrine effects $[48,49]$. All of these are essential components for the initiation and improvement of the inflammatory response, and their expression is also increased by the LPS stimulation of muscle cells $[3,4,50]$. Moreover, they can accelerate the inflammatory response by activating or increasing the expression of pro-inflammatory mediators as well as other pro-inflammatory cytokines [4,21]. Therefore, the level of pro-inflammatory cytokines has been applied as an indicator to evaluate anti-inflammatory efficacy in muscle cells. In the current study, we found that tCA reduced the production of TNF-a and IL-6 in LPS-stimulated C2C12 myoblasts by suppressing their expression. Consistent with our results, Kim et al. [51] also reported similar effects in RAW 264.7 macrophages stimulated with LPS, and these results well support the anti-inflammatory efficacy of tCA found in several experimental models [31,33,52].

Among various intracellular signaling pathways, NF- $\mathrm{kB}$ has been identified as the most important transcription factor in regulating the expression of pro-inflammatory factors by LPS stimulation $[53,54]$. Typically, NF-kB forms a complex with the inhibitory subunit IkB- $\alpha$ and remains inactive in the cytoplasm. When IKB- $\alpha$ is phosphorylated by IKK- $a / b$ and degraded through the ubiquitin-proteasomal pathway, NF-KB migrates to the nucleus, triggering transcriptional activation of inflammation-inducing genes and catabolic enzymes. As is well known, TLR4, a pathogen pattern receptor on the cell surface, can recruit MyD88 when bound to LPS to induce NF-KB activation $[55,56]$. TLR4/Myd88/NF-KB is known as a classical signaling pathway whose activation is consider to be responsible for the massive inflammation and considered to be a valuable and promising therapeutic target against inflammation related diseases [57-60]. Yu et al. [58] reported that Panax quinquefolius L. Saponins protect myocardial ischemia reperfusion through blocking TLR4/Myd88/NF-kB signaling pathway suggesting it can be potential therapeutic target pathway for preventing myocardial ischemia. More recently, $\mathrm{Xu}$ et al. demonstrated that metformin, a natural compound found in the plant Galega officinalis, suppress LPS-induced inflammatory response via blocking TLR4/ NF-kB signaling pathway in bovine mammary epithelial cells [60]. Therefore, to elucidate the mechanism of inhibition of the LPS-induced inflammatory response by $\mathrm{tCA}$, the expression levels of NF-kB, IкB- $a$, IKK- $a / b$, TLR4, and MyD88 were 
investigated. Our results showed that in LPS-stimulated $\mathrm{C} 2 \mathrm{C} 12$ cells, tCA effectively reversed the translocation of NF-KB from the cytoplasm to the nucleus, degradation of IKB- $\alpha$, and phosphorylation of IKK- $\mathrm{a} / \mathrm{b}$, an essential step for NF-KB activation. Consequently, it appears that the NF- $\mathrm{kB}$ pathway participated in the anti-inflammatory process of tCA, and these results are in good agreement with the anti-inflammatory mechanisms of this compound observed in several previous studies [28-31]. Furthermore, tCA suppressed LPS-induced expression of TLR4 and MyD88 proteins, and the level of LPS binding on the cell surface was significantly reduced in the cells pre-treated with tCA compared to untreated cells. These results suggest that tCA can inhibit LPS-mediated inflammatory action in C2C12 myoblasts by repressing TLR4-mediated NF-кB signaling through an antagonistic effect on the binding of LPS and TLR4.

Meanwhile, endogenous free radicals like ROS play an important role in host defense. However, excess ROS can cause oxidative damage to cellular macromolecules, and has been shown to play a key role in initiating and promoting inflammation-related diseases by upregulating the production of inflammatory mediators and cytokines [10,11]. According to our results, tCA strongly inhibited LPS-induced ROS formation in $\mathrm{C} 2 \mathrm{C} 12$ myoblasts and in zebrafish, supporting that the use of tCA as an antioxidant for the management of oxidative stress associated with inflammatory responses. HO-1, a typical cytoprotective and inducible enzyme, is one of the downstream anti-oxidative phase II enzymes dependent upon transcription factor Nrf2. For Nrf-2 to act as a transcription factor, it must be liberated from Kelch-like ECH-associated protein 1, a negative regulator of Nrf2, in the cytoplasm and phosphorylated before translocation to the nucleus $[61,62]$. Unlike HO-1, NOXs are key enzymes involved in the production of ROS as important regulators of redox homeostasis [63,64]. NOX consists of seven members, of which NOX2 acts as a major contributor of ROS generation during skeletal muscle contraction [65,66]. And NOX1, which is highly expressed in skeletal muscle along with NOX2 and NOX4 [65,67], is increased by myostatin in C2C12 myoblasts [68], but its physiological role in regulating ROS production has not been well identified. In addition, the accumulated evidence supports that the activation of NOX1 and NOX2 can participate in LPS-induced inflammatory responses as well as ROS production $[15,69,70]$. Therefore, we investigated the effect of tCA on the protein levels of Nrf2 and HO-1 in LPS-stimulated C2C12 myoblasts, and found that tCA increased their levels in the presence of LPS.
Additionally, the degree of phosphorylation of p-Nrf-2 was also markedly increased in cells co-treated with tCA and LPS compared to the group treated with tCA or LPS alone, indicating that the activity of Nrf-2 as a transcription factor was improved. However, pre-treatment with tCA inhibited the expression levels of NOX1 and NOX2 in LPS-stimulated $\mathrm{C} 2 \mathrm{C} 12$ myoblasts. These observations provide the possibility that tCA may be responsible for the anti-inflammatory and antioxidant effects in C2C12 myoblasts stimulated with LPS through mediating the Nrf2/HO-1 axis and the NOXs signaling pathway. However, the relationship between Nrf- 2 and the NOX signaling system and the role of their upstream regulators should be further investigated in the future. Moreover, further studies using HO-1 siRNA are needed to identify the role of tCA on the down-regulation of TLR4/NF-KB signaling pathway in LPS-stimulated C2C12 myoblasts. Since in vivo experiments can provide a better understanding of efficacy assessment at the organism level, the anti-inflammatory and antioxidant potential of tCA identified in $\mathrm{C} 2 \mathrm{C} 12$ myoblasts was further confirmed in the zebrafish model. The present results showed the ability of tCA to inhibit inflammatory and oxidative reactions in the LPS-microinjected zebrafish larvae model by reducing $\mathrm{NO}$ and ROS generation. Although these results support our in vitro results, additional mechanistic studies are needed to interpret the mechanisms related to the anti-inflammatory and antioxidant efficacy of tCA in in vivo model.

In summary, the current study showed that pro-inflammatory enzymes such as iNOS and COX-2 and cytokines including TNF- $\alpha$ and IL-6 were downregulated by tCA due to inhibition of the TLR4/NF-kB signaling pathway in LPS-stimulated C2C12 myoblasts. tCA also attenuated the accumulation of ROS, which was associated with the activation of the Nrf2/HO-1 signaling pathway and inhibition of NOXs proteins expression (Figure 8). In addition, Furthermore, the anti-inflammatory and antioxidant activities of tCA were also confirmed in an in vivo zebrafish model. Building on these results, tCA will provide a pharmacological basis for exciting future research in preventing and reducing the risk of various inflammation and oxidative stress-mediated muscle diseases.

\section{Acknowledgement}

This research was financially supported by

"Regional Specialized Industry Development Program (R\&D, S2874684)" supervised by the Korea Institute for Advancement of Technology (KIAT) and Ministry of SMEs and Startups (MSS). 


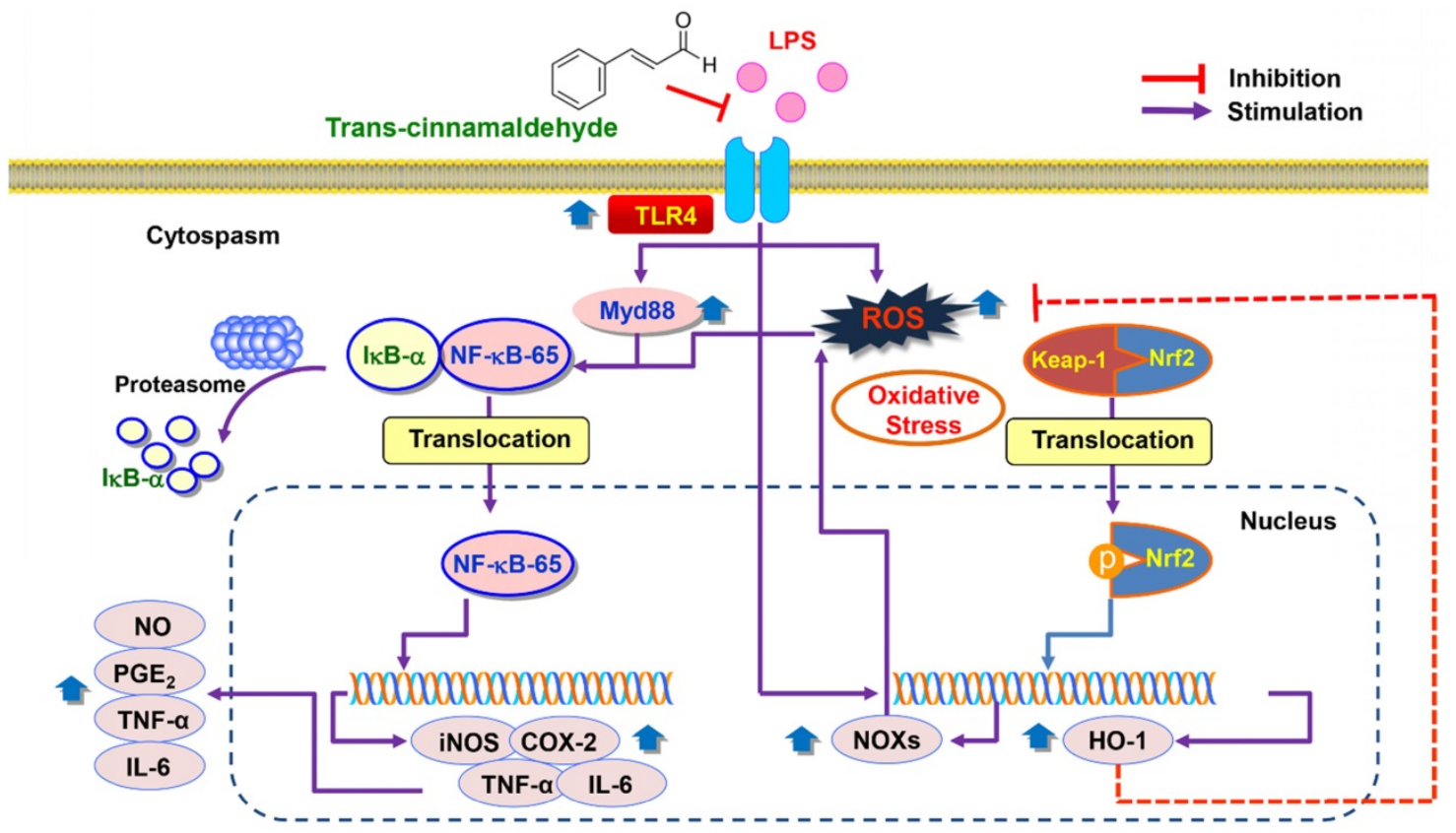

Figure 8. Proposed mechanism of anti-inflammatory and antioxidant effects of tCA in $\mathrm{C} 2 \mathrm{C} 12$ myoblasts.

\section{Competing Interests}

The authors have declared that no competing interest exists.

\section{References}

1. Iizuka K, Machida T, Hirafuji M. Skeletal muscle is an endocrine organ. J Pharmacol Sci. 2014;125:125-131.

2. Romagnoli C, Pampaloni B, Brandi ML. Muscle endocrinology and its relation with nutrition. Aging Clin Exp Res. 2019;31:783-792.

3. Frost RA, Lang $\mathrm{CH}$. Regulation of muscle growth by pathogen-associated molecules. J Anim Sci 2008:86(14 Suppl):E84-93.

4. Suzuki K, Tominaga T, Ruhee RT, Ma S. Characterization and modulation of systemic inflammatory response to exhaustive exercise in relation to oxidative stress. Antioxidants (Basel). 2020;9:401.

5. Kawanishi N, Tanaka Y, Kato Y, Shiva D, Yano H. Lipopolysaccharideinduced monocyte chemotactic protein-1 is enhanced by suppression of nitric oxide production, which depends on poor CD14 expression on the surface of skeletal muscle. Cell Biochem Funct. 2008;26:486-492.

6. Wyns H, Plessers E, De Backer P, Meyer E, Croubels S. In vivo porcine lipopolysaccharide inflammation models to study immunomodulation of drugs. Vet Immunol Immunopathol. 2015;166:58-69.

7. Aleem D, Tohid H. Pro-inflammatory cytokines, biomarkers, genetics and the immune system: A mechanistic approach of depression and psoriasis. Rev Colomb Psiquiatr. 2018;47:177-186.

8. Soufli I, Toumi R, Rafa H, Touil-Boukoffa C. Overview of cytokines and nitric oxide involvement in immuno-pathogenesis of inflammatory bowel diseases. World J Gastrointest Pharmacol Ther. 2016;7:353-360.

9. Förstermann U, Sessa WC. Nitric oxide synthases: regulation and function. Eur Heart J. 2012;33:829-837.

10. Bjørn ME, Hasselbalch HC. The role of reactive oxygen species in myelofibrosis and related neoplasms. Mediators Inflamm. 2015;2015:648090.

11. Liu Z, Ren Z, Zhang J, Chuang CC, Kandaswamy E, Zhou T, et al. Role of ROS and nutritional antioxidants in human diseases. Front Physiol. 2018;9:477.

12. Gugliandolo E, Fusco R, Licata P, Peritore AF, D'amico R, Cordaro M, et al. Protective Effect of hydroxytyrosol on LPS-induced inflammation and oxidative stress in bovine endometrial epithelial cell line. Vet Sci. 2020;7:161.

13. Gugliandolo E, Fusco R, D'Amico R, Peditto M, Oteri G, Di Paola R, et al. Treatment with a flavonoid-rich fraction of bergamot juice improved lipopolysaccharide-induced periodontitis in rats. Front Pharmacol. 2019;9:1563

14. Fusco R, Cordaro M, Siracusa R, Peritore AF, D'Amico R, Licata P, et al. Effects of hydroxytyrosol against lipopolysaccharide-induced inflammation and oxidative stress in bovine mammary epithelial cells: A natural therapeutic tool for bovine mastitis. Antioxidants (Basel). 2020;9:693.
15. Liu S, Adewole D, Yu L, Sid V, Wang B, OK, Yang C. Rutin attenuates inflammatory responses induced by lipopolysaccharide in an in vitro mouse muscle cell (C2C12) model. Poult Sci. 2019;98:2756-2764.

16. Utzeri E, Usai P. Role of non-steroidal anti-inflammatory drugs on intestinal permeability and nonalcoholic fatty liver disease. World J Gastroenterol. 2017;23:3954-3963.

17. Ferrer MD, Busquets-Cortés C, Capó X, Tejada S, Tur JA, Pons A, et al. Cyclooxygenase-2 inhibitors as a therapeutic target in inflammatory diseases. Curr Med Chem. 2019;26:3225-3241.

18. Zhang C, Fan L, Fan S, Wang J, Luo T, Tang Y, et al. Cinnamomum cassia Presl: A review of its traditional uses, phytochemistry, pharmacology and toxicology. Molecules. 2019;24:3473.

19. Zhao Y, Deng H, Li K, Wang L, Wu Y, Dong X, et al. Trans-cinnamaldehyde improves neuroinflammation-mediated NMDA receptor dysfunction and memory deficits through blocking NF-kappaB pathway in presenilin1/2 conditional double knockout mice. Brain Behav Immun. 2019;82:45-62.

20. Wang J, Su B, Jiang H, Cui N, Yu Z, Yang Y, et al. Traditional uses, phytochemistry and pharmacological activities of the genus Cinnamomum (Lauraceae): A review. Fitoterapia. 2020;146:104675.

21. Zhang JH, Liu LQ, He YL, Kong WJ, Huang SA. Cytotoxic effect of trans-cinnamaldehyde on human leukemia K562 cells. Acta Pharmacol Sin. 2010;31:861-866

22. Pyo JH, Jeong YK, Yeo S, Lee JH, Jeong MY, Kim SH, et al. Neuroprotective effect of trans-cinnamaldehyde on the 6-hydroxydopamine-induced dopaminergic injury. Biol Pharm Bull. 2013;36:1928-1935.

23. Gannon NP, Schnuck JK, Mermier CM, Conn CA, Vaughan RA. trans-Cinnamaldehyde stimulates mitochondrial biogenesis through PGC-1alpha and PPARbeta/delta leading to enhanced GLUT4 expression. Biochimie. 2015;119:45-51.

24. Fu Y, Yang $\mathrm{P}$, Zhao $\mathrm{Y}$, Zhang L, Zhang Z, Dong $X$, et al. trans-Cinnamaldehyde inhibits microglial activation and improves neuronal survival against neuroinflammation in BV2 microglial cells with lipopolysaccharide stimulation. Evid Based Complement Alternat Med. 2017;2017:4730878.

25. Davaatseren M, Jo YJ, Hong GP, Hur HJ, Park S, Choi MJ. Studies on the anti-oxidative function of trans-cinnamaldehyde-included beta-cyclodextrin complex. Molecules. 2017;22:1868

26. Chiang YF, Chen HY, Huang KC, Lin PH, Hsia SM. Dietary antioxidant trans-cinnamaldehyde reduced visfatin-induced breast cancer progression: In vivo and in vitro study. Antioxidants (Basel). 2019;8:625.

27. Wu JR, Zhong WJ, Chen ZD, Zhu BQ, Jiang YY, Wierzbicki PM. The protective impact of trans-cinnamaldehyde (TCA) against the IL-1b induced inflammation in in vitro osteoarthritis model by regulating PI3K/AKT pathways. Folia Histochem Cytobiol. 2020;58:264-271.

28. Wang $\mathrm{M}$, Yan S, Zhou $\mathrm{Y}$, Xie P. trans-Cinnamaldehyde reverses depressive-like behaviors in chronic unpredictable mild stress rats by inhibiting NF-kappaB/NLRP3 inflammasome pathway. Evid Based Complement Alternat Med. 2020;2020:4572185.

29. Xia T, Gao R, Zhou G, Liu J, Li J, Shen J. Trans-cinnamaldehyde inhibits IL-1beta-stimulated inflammation in chondrocytes by suppressing NF-kappaB and p38-JNK pathways and exerts chondrocyte protective effects in a rat model of osteoarthritis. Biomed Res Int. 2019;2019:4039472. 
30. Chen YF, Wang YW, Huang WS, Lee MM, Wood WG, Leung YM, et al. Trans-cinnamaldehyde, an essential oil in cinnamon powder, ameliorates cerebral ischemia-induced brain injury via inhibition of neuroinflammation through attenuation of iNOS, COX-2 expression and NF kappa-B signaling pathway. Neuromolecular Med. 2016;18:322-333.

31. Schink A, Naumoska K, Kitanovski Z, Kampf CJ, Fröhlich-Nowoisky J, Thines E, et al. Anti-inflammatory effects of cinnamon extract and identification of active compounds influencing the TLR2 and TLR4 signaling pathways. Food Funct. 2018;9:5950-5964.

32. Ryu JS, Kang HY, Lee JK. Effect of treadmill exercise and trans-cinnamaldehyde against d-galactose- and aluminum chloride-induced cognitive dysfunction in mice. Brain Sci. 2020;10:793.

33. Abou El-Ezz D, Maher A, Sallam N, El-Brairy A, Kenawy S. Trans-cinnamaldehyde modulates hippocampal Nrf2 factor and inhibits amyloid beta aggregation in LPS-induced neuroinflammation mouse model. Neurochem Res. 2018;43:2333-2342.

34. Choi YH. trans-Cinnamaldehyde prevents oxidative stress-induced apoptosis in V79-4 Chinese hamster lung fibroblasts through the Nrf2-mediated HO-1 activation. Biol Pharm Bull. 2020;43:1707-1714.

35. Choi YH. Trans-cinnamaldehyde protects $\mathrm{C} 2 \mathrm{C} 12$ myoblasts from DNA damage, mitochondrial dysfunction and apoptosis caused by oxidative stress through inhibiting ROS production. Genes Genomics. 2020. doi: $10.1007 /$ s13258-020-00987-9.

36. Chae BS. Effect of low-dose corticosterone pretreatment on the production of inflammatory mediators in super-low-dose LPS-primed immune cells. Toxicol Res. 2020;37:47-57

37. Park JW, Lee SJ, Kim JE, Kang MJ, Bae SJ, Choi YJ, et al. Comparison of response to LPS-induced sepsis in three DBA/2 stocks derived from different sources. Lab Anim Res. 2021;37:2.

38. Park S, Kim M, Hong $Y$, Lee $H$, Tran Q, Kim C, et al. Myristoylated TMEM39AS41, a cell-permeable peptide, causes lung cancer cell death. Toxicol Res. 2020;36:123-130.

39. Murshid A, Gong J, Prince T, Borges TJ, Calderwood SK. Scavenger receptor SREC-I mediated entry of TLR4 into lipid microdomains and triggered inflammatory cytokine release in RAW 264.7 cells upon LPS activation. PLoS One. 2015;10:e122529.

40. Choi YH. Catalpol attenuates lipopolysaccharide-induced inflammatory responses in BV2 microglia through inhibiting the TLR4-mediated NF-kappaB pathway. Gen Physiol Biophys. 2019;38:111-122.

41. Hwangbo H, Kim SY, Lee H, Park SH, Hong SH, Park C, et al. Auranofin enhances sulforaphane-mediated apoptosis in hepatocellular carcinoma Hep3B cells through inactivation of the PI3K/Akt signaling pathway. Biomol Ther (Seoul). 2020;28:443-455.

42. Jeong JW, Cha HJ, Han MH, Hwang SJ, Lee DS, Yoo JS, et al. Spermidine protects against oxidative stress in inflammation models using macrophages and zebrafish. Biomol Ther (Seoul). 2018;26:146-156.

43. Saini R, Singh S. Inducible nitric oxide synthase: An asset to neutrophils. J Leukoc Biol. 2019:105:49-61.

44. Yao C, Narumiya S. Prostaglandin-cytokine crosstalk in chronic inflammation. Br J Pharmacol. 2019;176:337-354.

45. Lee MY, Sun KH, Chiang CP, Huang CF, Sun GH, Tsou YC, Liu HY, Tang SJ. Nitric oxide suppresses LPS-induced inflammation in a mouse asthma model by attenuating the interaction of IKK and Hsp90. Exp Biol Med (Maywood). 2015;240:498-507.

46. Raychaudhuri B, Dweik R, Connors MJ, Buhrow L, Malur A, Drazba J, et al. Nitric oxide blocks nuclear factor-kappa B activation in alveolar macrophages. Am J Respir Cell Mol Biol. 1999;21:311-311.

47. Wink DA, Hines $\mathrm{HB}$, Cheng RY, Switzer $\mathrm{CH}$, Flores-Santana W, Vitek MP, et al. Nitric oxide and redox mechanisms in the immune response. J Leukoc Biol. 2011;89:873-91.

48. Wang T, He C, Yu X. Pro-inflammatory cytokines: New potential therapeutic targets for obesity-related bone disorders. Curr Drug Targets. 2017;18:1664-1675.

49. Hu F, Lou N, Jiao J, Guo F, Xiang H, Shang D. Macrophages in pancreatitis: Mechanisms and therapeutic potential. Biomed Pharmacother. 2020;131:110693.

50. Gordon BS, Kelleher AR, Kimball SR. Regulation of muscle protein synthesis and the effects of catabolic states. Int J Biochem Cell Biol. 2013;45:2147-2157.

51. Kim ME, Na JY, Lee JS. Anti-inflammatory effects of trans-cinnamaldehyde on lipopolysaccharide-stimulated macrophage activation via MAPKs pathway regulation. Immunopharmacol Immunotoxicol. 2018;40:219-224.

52. Zhang $L$, Zhang $Z, F u$, Y Yang $P$, Oin $Z$, Chen $Y$, et al. Trans-cinnamaldehyde improves memory impairment by blocking microglial activation through the destabilization of iNOS mRNA in mice challenged with lipopolysaccharide. Neuropharmacology. 2016;110 (Pt A):503-518.

53. Doyle SL, O'Neill LA. Toll-like receptors: from the discovery of NFkappaB to new insights into transcriptional regulations in innate immunity. Biochem Pharmacol. 2006;72:1102-1113.

54. Hernandez A, Patil NK, Stothers CL, Luan L, McBride MA, Owen AM, et al. Immunobiology and application of toll-like receptor 4 agonists to augment host resistance to infection. Pharmacol Res. 2019;150:104502.

55. Rigoglou S, Papavassiliou AG. The NF-kappaB signalling pathway in osteoarthritis. Int J Biochem Cell Biol. 2013;45:2580-2584.

56. Schuliga M. NF-kappaB signaling in chronic inflammatory airway disease. Biomolecules. 2015;5:1266-1283.
57. Gugliandolo E, Fusco R, Ginestra G, D'amico R, Bisignano C, Mandalari G, et al. Involvement of TLR4 and PPAR-a receptors in host response and NLRP3 inflammasome activation, against pulmonary infection with Pseudomonas Aeruginosa. Shock. 2019;51:221-227.

58. Yu P, Li Y, Fu W, Li X, Liu Y, Wang Y, et al. Panax quinquefolius L. Saponins protect myocardial ischemia reperfusion no-reflow through inhibiting the activation of NLRP3 inflammasome via TLR4/MyD88/NF-kB signaling pathway. Front Pharmacol. 2021;11:607813.

59. Yang Y, Lv J, Jiang S, Ma Z, Wang D, Hu W, et al. The emerging role of Toll-like receptor 4 in myocardial inflammation. Cell Death Dis. 2016;7:e2234.

60. Xu T, Wu X, Lu X, Liang Y, Mao Y, Loor JJ, et al. Metformin activated AMPK signaling contributes to the alleviation of LPS-induced inflammatory responses in bovine mammary epithelial cells. BMC Vet Res. 2021;17(1):97.

61. Loboda A, Damulewicz M, Pyza E, Jozkowicz A, Dulak J. Role of Nrf2/HO-1 system in development, oxidative stress response and diseases: an evolutionarily conserved mechanism. Cell Mol Life Sci. 2016;73:3221-3247.

62. Saha S, Buttari B, Panieri E, Profumo E, Saso L. An overview of Nrf2 signaling pathway and its role in inflammation. Molecules. 2020;25:5474.

63. Ewald CY. Redox signaling of NADPH oxidases regulates oxidative stress responses, immunity and aging. Antioxidants (Basel). 2018;7:130.

64. Waghela BN, Vaidya FU, Agrawal Y, Santra MK, Mishra V, Pathak C. Molecular insights of NADPH oxidases and its pathological consequences. Cell Biochem Funct. 2020. doi: 10.1002/cbf.3589.

65. Ferreira LF, Laitano O. Regulation of NADPH oxidases in skeletal muscle. Free Radic Biol Med. 2016;98:18-28

66. Hord JM, Garcia MM, Farris KR, Guzzoni V, Lee Y, Lawler MS, et al. Nox2 signaling and muscle fiber remodeling are attenuated by losartan administration during skeletal muscle unloading. Physiol Rep. 2021;9:e14606.

67. Piao YJ, Seo YH, Hong F, Kim JH, Kim YJ, Kang MH, et al. Nox 2 stimulates muscle differentiation via NF-kappaB/iNOS pathway. Free Radic Biol Med. 2005;38:989-1001.

68. Sriram S, Subramanian S, Sathiakumar D, Venkatesh R, Salerno MS, McFarlane CD, et al. Modulation of reactive oxygen species in skeletal muscle by myostatin is mediated through NF-kappaB. Aging Cell. 2011;10:931-948.

69. O'Leary DP, Bhatt L, Woolley JF, Gough DR, Wang JH, Cotter TG, et al. TLR-4 signalling accelerates colon cancer cell adhesion via NF-KB mediated transcriptional up-regulation of Nox-1. PLoS One. 2012;7:e44176.

70. Chai $Y$, Cao Z, Yu R, Liu Y, Yuan D, Lei L. Dexmedetomidine attenuates LPS-induced monocyte-endothelial adherence via inhibiting Cx43/PKCalpha/NOX2/ROS signaling pathway in monocytes. Oxid Med Cell Longev. 2020;2020:2930463. 